\title{
Longterm olsalazine treatment: pharmacokinetics, tolerance and effects on local eicosanoid formation in ulcerative colitis and Crohn's colitis
}

\author{
K LAURITSEN, L STæRK LAURSEN, K BUKHAVE, AND J RASK-MADSEN \\ From the Department of Medical Gastroenterology, Odense University Hospital, Odense and Sections of \\ Gastroenterology, Department of Medicine C, Herlev Hospital and Department of Medicine B, \\ Bispebjerg Hospital, University of Copenhagen, Copenhagen, Denmark.
}

SUMmary To examine pharmacokinetics and tolerance of long term administration of olsalazine (azodisalicylate), increasing doses of the drug were given for one year to 31 patients with ulcerative colitis (UC) and nine patients with Crohn's colitis (CC), refractory to, or intolerant of sulphasalazine, until sustained remission was obtained or a maximum of $4 \mathrm{~g} / \mathrm{day}$ was reached. Colonic drug metabolism was studied by equilibrium in vivo dialysis of faeces. Complete azoreduction occurred in most cases. Concentrations of 5-aminosalicylic acid, but not $\mathbf{N}$-acetyl-5aminosalicylic acid, in faecal dialysates increased dose dependently. Serum concentrations disclosed no cumulation in the long term and olsalazine was well tolerated, although loose stools occurred transiently in some patients with extensive disease: this was associated with a larger proportion of unsplit olsalazine in the faecal dialysates. Patients with ulcerative colitis having a high prostaglandin $E_{2}$ concentration $(>30 \mathrm{ng} / \mathrm{ml})$ determined by equilibrium dialysis of rectum, were less likely to benefit from treatment. Olsalazine is a very effective means of delivery of 5-aminosalicylic acid to the colonic mucosa in active disease. Use of the drug in controlled trials may be considered safe even in prolonged high dosage.

Two major challenges to the novel sulphasalazine like drugs ${ }^{1-3}$ are whether they can be established through controlled trials to benefit those patients with ulcerative colitis (UC) who are either refractory to or intolęrant of sulphasalazine. Although effective as longterm maintenance treatment in the prevention of relapse,,$^{45}$ a large proportion of patients do not obtain complete remission and often experience relapses despite the administration of sulphasalazine. Furthermore, $10-20 \%$ of patients are allergic to or otherwise intolerant of sulphasalazine. ${ }^{\circ}$ This is believed to be caused mainly by sulphapyridine, which is readily absorbed when split in the colon by

Address for correspondence: Dr Jørgen Rask-Madsen, Section of Gastroenterology, Department of Medicine B. Bispebjerg Hospital, DK-2400 Copenhagen NV, Denmark.

Received for publication 12 February 1988. bacterial azoreductases from the active therapeutic ingredient, ${ }^{, 11} 5$-aminosalicylic acid (5-ASA). Novel sulphur free drugs designed in an attempt to circumvent drug intolerance provide the opportunity to investigate the remaining question: 'to what extent are insufficiently high intraluminal concentrations of 5-ASA the cause of sulphasalazine resistance?' The efficacy of sulphasalazine in preventing relapse in UC seems to be dose dependent but the dose may only be raised with an increase in side effects. "Although the drug is effective in Crohn's colitis (CC) $)^{12}$ and mildly to moderately active $\mathrm{UC},{ }^{13}$ it is considerably less effective than glucocorticoids, whereas topical treatment with 5-ASA appears as effective ${ }^{14}$ or even more effective, ${ }^{15}$ than treatment with glucocorticoid enemas in distally located UC. Oral olsalazine seems promising in the treatment of inflammatory bowel disease because it consists of two molecules of 5-ASA also linked by an azo bond. ${ }^{16}$ 
The purpose of the present study was to determine the metabolism of olsalazine in the colon and the drug tolerance during longterm administration of high doses in colitis patients not satisfactorily treated with sulphasalazine - that is, in patients with UC or $\mathrm{CC}$ refractory to or intolerant of sulphasalazine. Luminal concentrations of prostaglandin $\mathrm{E}_{2}\left(\mathrm{PGE}_{2}\right)$ and leucotriene $\mathrm{B}_{4}\left(\mathrm{LTB}_{4}\right)$ were also determined during the treatment period to study whether these highly sensitive markers of disease activity ${ }^{1718}$ might predict the outcome of treatment.

\section{Methods}

PATIENTS

Patients fulfilling the following entry criteria were included in the study: (a) proven $\mathrm{UC}^{19}$ or proven $\mathrm{CC}:{ }^{20}$ (b) relapsing disease - that is, a relapse within the past six months, or chronic continuous disease activity - that is, absence of remission (definition: see below) for three months or more; (c) refractory to sulphasalazine - that is, relapsing disease despite maintenance treatment with sulphasalazine $2 \mathrm{~g}$ /day or chronic continuous disease despite treatment with glucocorticoids and sulphasalazine, or intolerant of sulphasalazine - that is, allergic to or otherwise intolerant of sulphasalazine.

Patients below 18 or above 80 years of age were excluded, as were women who were pregnant or lactating and those with childbearing potential not using oral contraception or an intrauterine device. Furthermore, patients with CC, who had also radiologically verified small bowel disease were excluded.

Each patient gave informed consent and the study was approved by the Ethical Committee of Funen and Vejle Counties.

\section{EXPERIMENTAL DESIGN}

The study design was open with an initial dose of $1 \mathrm{~g} /$ day $(0.5 \mathrm{~g}$ bid) in sulphasalazine intolerant patients. In sulphasalazine refractory patients the initial dose was $2 \mathrm{~g} /$ day $(1 \mathrm{~g}$ bid) with no washout period after cessation. The dose was gradually increased at the scheduled visits until the endpoint was reached - that is, sustained remission-as defined below, or drug intolerance occurred, or a maximum of $4 \mathrm{~g} /$ day ( $1 \mathrm{~g}$ qid) equivalent to approximately 10 $\mathrm{g} /$ day of sulphasalazine as regards 5-ASA on a molar basis. In patients on concomitant corticosteroids the dose was gradually tapered when clinically inactive disease (see below) occurred and, if possible, the administration was stopped.

A one year treatment period was planned including scheduled visits at two weeks and at two, four, six, eight, 10, and 12 months, in addition to inbetween visits, if needed. Before entry and at each visit the clinical disease activity was assessed (see below) and a laboratory screening was done. This included blood haemoglobin, reticulocyte count, erythrocyte sedimentation rate, leucocyte count, leucocyte differential count, platelet count, serum concentrations of $\mathrm{Na}, \mathrm{K}, \mathrm{Ca}$, albumin, creatinine, urea, alanine aminotransferase, lactate dehydrogenase, alkaline phosphatase, bilirubin, and plasma prothrombin, in addition to urine analysis for protein and glucose and microscopy for erythrocytes, leucocytes, and casts. Additional serum was obtained before the administration of the morning dose of olsalazine for determination of olsalazine, 5-ASA, and Ac-5-ASA.

Before entry, at the two weeks' visit, and at the six and 12 months' visits equilibrium in vivo dialysis of faeces $^{16}$ as well as equilibrium in vivo dialysis of rectum $^{17}$ were done before endoscopy of rectum and sigmoid colon with biopsies. The patients had been at a particular dose level of olsalazine for two weeks or more before these measurements were performed.

Olsalazine (Dipentum, Pharmacia AB, Uppsala, Sweden) was administered in gelatin capsules, each containing $250 \mathrm{mg}$ of the powdered drug without additives. Compliance to prescription was estimated at each study visit by counting the number of returned olsalazine capsules.

DISEASE ACTIVITY

The disease activity was graded according to a four scaled semiquantitative grading: ${ }^{1721}$ (a) clinical activity: inactive $\left(\mathrm{C}_{0}\right)$, mild $\left(\mathrm{C}_{1}\right)$, moderate $\left(\mathrm{C}_{2}\right)$, severe $\left(\mathrm{C}_{3}\right)$; (b) endoscopic activity: inactive $\left(\mathrm{E}_{0}\right)$, mild $\left(E_{1}\right)$, moderate $\left(E_{2}\right)$, severe $\left(E_{3}\right)$; and $(c)$ histological activity: inactive $\left(\mathrm{H}_{0}\right)$, mild $\left(\mathrm{H}_{1}\right)$, moderate $\left(\mathrm{H}_{2}\right)$, severe $\left(\mathrm{H}_{3}\right)$.

The clinical activity was based on a diary and the objective findings registered by the investigator. To minimise variation among observers ${ }^{22}$ each patient was examined on all study days by the same investigator. All days the last week preceding a scheduled visit the patient recorded the number of bowel movements in the diary, in addition to the presence or absence of blood, and graded abdominal pain and general wellbeing according to Best et $\mathrm{l}^{23}$ for calculation of the Crohn's disease activity index (CDAI).

Remission in patients with UC was defined as clinically inactive disease $\left(\mathrm{C}_{0}-\right.$ that is, below three bowel movements a day without blood present) and no evidence of inflammation $\left(\mathrm{E}_{0}\right)$ on sigmoidoscopy. Remission in patients with CC was defined as a CDAI $<150$ and no evidence of inflammation on sigmoidoscopy. Patients in whom remission did not occur without concomitant use of corticosteroids were classified as treatment failures. Because of the open design of the study no further clinical or endoscopic estimations of efficacy were done. 
Table 1 Description of patients

\begin{tabular}{lll}
\hline & $\begin{array}{l}\text { Ulcerative } \\
\text { colitis }(n=31)\end{array}$ & $\begin{array}{c}\text { Crohn's } \\
\text { colitis }(n=9)\end{array}$ \\
\hline Age, mean year (range) & $34(19-66)$ & $28(18-34)$ \\
Sex, male/female & $16 / 15$ & $2 / 7$ \\
Smokers/non-smokers & $3 / 28$ & $7 / 2$ \\
Duration of disease, mean year (range) & $6 \cdot 7(1 \cdot 8-19)$ & $5 \cdot 8(3 \cdot 0-10)$ \\
Continuously active/intermittently & $20 / 11$ & $7 / 2$ \\
$\quad$ active disease (during previous year) & & \\
Sulphasalazine, refractory/intolerant & $23 / 8$ & $8 / 1$ \\
Extensive disease (total/'left sided') & $12 / 19$ & $9 / 0$ \\
& & \\
\hline
\end{tabular}

IN VIVO DIALYSIS METHODS

Equilibrium in vivo dialysis of faeces was done as previously described in detail ${ }^{16}$ by pooling the contents of five swallowed dialysis bags after their intestinal transit (faecal dialysate). These dialysates were analysed for concentrations of olsalazine, 5-ASA, and Ac-5-ASA, in addition to $\mathrm{PGE}_{2}$ (faecal $\mathrm{PGE}_{2}$ ).

Equilibrium in vivo dialysis of rectum was carried out after insertion of a $12 \mathrm{~cm}$ long dialysis bag into the emptied rectum as previously described. ${ }^{17}$ The bag was left for four hours and its contents (rectal dialysate) were analysed for concentrations of $\mathrm{PGE}_{2}$ (rectal $\mathrm{PGE}_{2}$ ) and $\mathrm{LTB}_{4}\left(\right.$ rectal $\left.\mathrm{LTB}_{4}\right)$.

\section{ANALYTICAL PROCEDURES}

Determination of olsalazine, 5-ASA, and Ac-5-ASA in serum and faecal dialysates were done by high performance liquid chromatography (HPLC) as previously described. ${ }^{16}$ The lower detection limits in serum and in faecal dialysates were $1.0 \mu \mathrm{mol} / \mathrm{l}$ and $6 \cdot 0 \mu \mathrm{mol} / \mathrm{l}$, respectively.

Prostaglandin $E_{2}$ was measured by a radioimmunological method ${ }^{24}$ validated by gas chromatography mass spectrometry ${ }^{25}$ and $\mathrm{LTB}_{4}$ by reversed phase HPLC. ${ }^{17}$

These measurements were done blind and independent of the assessment of disease activity and clinicians were unaware of the results until the data had been completed.

\section{REFLECTIONS ON SAMPLE SIZE}

In planning the study it was considered relevant to compare colonic olsalazine metabolism and tolerance, (a) in patients with extensively located colitis and in patients with 'left-sided' colitis, (b) in sulphasalazine refractory patients and in sulphasalazine

Table 2 Adverse events reported during olsalazine treatment in 31 patients with ulcerative colitis (UC) and nine patients with Crohn's colitis (CC)

\begin{tabular}{|c|c|c|c|c|c|c|c|}
\hline \multicolumn{4}{|c|}{ Patient characteristics } & \multicolumn{4}{|l|}{ Adverse event } \\
\hline $\begin{array}{l}\text { Patient } \\
\text { no }\end{array}$ & Disease & $\begin{array}{l}\text { Intolerant } \\
\text { of SAZ }\end{array}$ & $\begin{array}{l}\text { Extensive } \\
(\text { E)/left } \\
\text { sided }(L S)\end{array}$ & $\begin{array}{l}\text { Description } \\
\text { of event }\end{array}$ & $\begin{array}{l}\text { Visit when } \\
\text { reported }\end{array}$ & $\begin{array}{l}\text { Olsalazine } \\
\text { dosage } \\
\text { (g/day) }\end{array}$ & Comment \\
\hline 5 & UC & No & LS & Bony pain & 10 months & 4 & Disappeared during continuous medication \\
\hline 6 & $\mathrm{UC}$ & No & $\mathrm{E}$ & Loose stools & 10 months & 4 & $\begin{array}{l}\text { Occurred transiently when dosage was increased from } 3 \\
\text { g/day }\end{array}$ \\
\hline 15 & $\mathrm{UC}$ & Yes & $\mathrm{E}$ & Loose stools & 2 wecks & 2 & $\begin{array}{l}\text { Persistent intolerance at } 2 \mathrm{~g} / \text { day; dosage reduced to } 1 \mathrm{~g} / \text { day; } \\
\text { proctocolectomy after } 7 \text { months }\end{array}$ \\
\hline 16 & UC & No & $\mathrm{E}$ & Loose stools & 2 weeks & 2 & Dosage temporarily reduced; later $4 \mathrm{~g}$ /day was tolerated \\
\hline & & & & Joint pain & 10 months & 4 & Disappeared during continuous medication \\
\hline 17 & $\mathrm{UC}$ & Yes & E & $\begin{array}{l}\text { Increased stool } \\
\text { frequency }\end{array}$ & 6 months & 2 & $\begin{array}{l}\text { Occurred when dosage was increased from } 1 \mathrm{~g} / \text { day; dosage } \\
\text { temporarily reduced; later } 2 \mathrm{~g} / \text { day was tolerated }\end{array}$ \\
\hline 19 & UC & Yes & LS & Loose stools & 2 weeks & 2 & $\begin{array}{l}\text { Occurred when dosage was increased from } 1 \mathrm{~g} / \text { day; dosage } \\
\text { temporarily reduced; later } 4 \mathrm{~g} / \text { day was tolerated }\end{array}$ \\
\hline 27 & $\mathrm{CC}$ & No & $\mathrm{E}$ & Loose stools & 6 months & 3 & $\begin{array}{l}\text { Occurred transiently when dosage was increased from } 2 \\
\text { g/day; later } 4 \mathrm{~g} / \text { day was tolerated }\end{array}$ \\
\hline 31 & $\mathrm{CC}$ & No & $\mathrm{E}$ & Loose stools & 2 months & 4 & $\begin{array}{l}\text { Persistent intolerance at } 4 \mathrm{~g} / \text { day; dosage reduced; } \\
\text { proctocolectomy after } 8 \text { months }\end{array}$ \\
\hline 32 & UC & No & $\mathrm{E}$ & Loose stools & 11 months & 4 & $\begin{array}{l}\text { Clinical and endoscopic relapse; corticosteroids were } \\
\text { administered and a reduced dosage of } 3 \text { g/day was } \\
\text { tolerated }\end{array}$ \\
\hline 34 & $\mathrm{CC}$ & No & $\mathrm{E}$ & Loose stools & 2 weeks & 2 & $\begin{array}{l}\text { Pcrsistent intolerance at } 2 \mathrm{~g} / \text { day; dosage reduced to } 1 \mathrm{~g} / \text { day; } \\
\text { stopped treatment after } 10 \text { months }\end{array}$ \\
\hline 35 & $\mathrm{CC}$ & No & $\mathrm{E}$ & Loose stools & 2 weeks & 2 & $\begin{array}{l}\text { Dosage temporarily reduced to } 1 \mathrm{~g} / \text { day; later } 3 \mathrm{~g} / \text { day was } \\
\text { tolerated }\end{array}$ \\
\hline 40 & UC & No & LS & Loose stools & 6 months & 4 & $\begin{array}{l}\text { Occurred when dosage was increased from } 3 \mathrm{~g} / \text { day; dosage } \\
\text { temporarily reduced; later } 4 \mathrm{~g} / \text { day was tolerated }\end{array}$ \\
\hline
\end{tabular}


Table 3 Concentrations of olsalazine, 5-ASA, and Ac-5-ASA in faecal dialysates of patients with ulcerative colitis: averages in each patient for each dosage of olsalazine (each patient had been on the particular dose level for at least two weeks)

\begin{tabular}{|c|c|c|c|c|c|}
\hline & & \multicolumn{4}{|l|}{ Olsalazine dose/day } \\
\hline & & $\lg (n=7)$ & $2 g(n=20)$ & $3 g(n=14)$ & $4 g(n=18)$ \\
\hline Olsalazine & $\mathrm{mmol} / \mathrm{l}$ & $0.10(0.14)[<0.006-0.72]$ & $0.34(0.48)[<0.006-1.7]$ & $0.40(0.58) \mid<0.006-2.0]$ & $0.27(0.41)[<0.006-1.4]$ \\
\hline 5-ASA & $\mathrm{mmol} / \mathrm{l}$ & $5.7(4.9) \mid<1.0-18]$ & $8 \cdot 0(6 \cdot 1) \mid<1 \cdot 0-31]$ & $13(11) \mid<1 \cdot 0-37]$ & $23(12)[6 \cdot 7-55]$ \\
\hline Ac-5-ASA & $\mathrm{mmol} / \mathrm{l}$ & $11(8 \cdot 5)[<0 \cdot 7-26]$ & $9.5(9.0)[<0.7-60]$ & $7 \cdot 5(8.2) \mid<0.7-26]$ & $11(5 \cdot 6)[2 \cdot 0-26]$ \\
\hline Total 5-ASA & $\mathrm{mmol} / \mathrm{l}$ & $17(9 \cdot 0)[<1.7-40]$ & $18(14)[<1 \cdot 7-72]$ & $20(18)[<1 \cdot 7-63]$ & $34(17)[8 \cdot 6-75]$ \\
\hline
\end{tabular}

5-ASA =5-aminosalicylic acid; Ac-5-ASA = acetyl-5-aminosalicylic acid. Values represent means (SD) [range]

intolerant patients, (c) in patients with chronic continuously active disease and in patients with intermittently active disease, (d) in patients with active disease $\left(\mathrm{C}_{1}-\mathrm{C}_{3}\right)$ and in patients without disease activity $\left(\mathrm{C}_{0}\right)$, and $(\mathrm{e})$ in patients with $\mathrm{UC}$ and in patients with CC. For each such comparison a group size of eight to 12 was considered to provide relevant phamacological information. As many patients would fit into more than one category, however, it was estimated that inclusion of a total of 40 to 50 patients in the study would be desirable.

STATISTICAL ANALYSES

The changes, if any, in safety variables after entry were tested for trends using the paired $t$ test and the Wilcoxon's matched pairs signed-ranks test, as appropriate. The Mann-Whitney $U$-test for unpaired variates was also used. Values of $p<0.05$ were considered significant.

\section{Results}

\section{DESCRIPTION OF PATIENTS}

Forty patients (31 with UC and nine with CC) consecutively entered the study within a six month period. Table 1 describes patient characteristics.

Among the 31 patients with UC the mean duration of treatment was $3 \dot{4} 1$ days (range 132-398 days) and the mean daily dosage of olsalazine (calculated as the ratio between the total dose in the treatment period and the number of days of treatment) was $2.6 \mathrm{~g} /$ day (range 1.0-3.6 g/day). For the nine patients with CC the similar figures were 319 days (range 93-383 days) and $2.5 \mathrm{~g} /$ day (range 1.0-3.5 g/day). The numbers of patients with UC on the individual daily dosages of olsalazine of $1 \mathrm{~g}, 2 \mathrm{~g}, 3 \mathrm{~g}$, and $4 \mathrm{~g}$ were $12,29,21$, and 22 , respectively. For patients with $\mathrm{CC}$ the similar figures were $3,8,5$, and 4 , respectively. Twenty six patients (four with $\mathrm{CC}$ ) received $4 \mathrm{~g}$ /day for up to 257 days.

WITHDRAWALS, TOLERANCE, AND SAFETY Eight patients did not complete the planned one year treatment period: two patients with UC and one with
$\mathrm{CC}$ had a colectomy carried out because of lack of efficacy after four, seven, and eight months, respectively. One patient with a 12 year history of UC had a colectomy after six months' treatment because biopsies revealed a rectal mucosal adenocarcinoma. Three patients wished to stop treatment prematurely, in two cases because of lack of efficacy (one with UC after eight months, one with $\mathrm{CC}$ after 10 months), and a third with $\mathrm{CC}$ after three months because she was in complete remission. Finally, one patient with UC in remission was excluded after eight months because he had not taken the study medicine.

Tolerance problems associated with olsalazine treatment (Table 2), such as loose or watery stools and/or increased stool frequency, were reported in 11 cases (seven with UC, four with CC). The tolerance problems typically developed at the start of olsalazine administration or shortly after an increase in dosage (Table 2). Symptoms of intolerance occurred most often (nine cases) in patients with extensively located disease and active disease (nine cases), but was transient in eight cases - that is, resolved within a few weeks during continuous administration of the drug. No patients were withdrawn because of drug intolerance.

Two patients reported transient pain in the bones and joints, respectively (Table 2 ). The Wilcoxon's matched pairs signed-ranks test revealed no significant differences in laboratory screening values before and after the trial. In six cases slightly increased concentrations of alanine aminotransferase or alkaline phosphatase were found, but the values became normal during continuous treatment.

CONCENTRATIONS OF OLSALAZINE,

5-AMINOSALICYLIC ACID, AND ACETYL-5AMINOSALICYLIC ACID IN FAECAL DIALYSATES The average concentrations of olsalazine, 5-ASA, Ac-5-ASA, and total 5-ASA (5-ASA + Ac-5-ASA) measured in faecal dialysates from each patient were calculated for each dose of olsalazine. The results obtained in patients with UC are given in Table 3. The results obtained in the nine patients with $\mathrm{CC}$ were within the range of those obtained in UC 
Table 4 Mean concentrations of olsalazine in serum and 5-ASA and Ac-5-ASA in faecal dialysates in patients with active $\left(\mathrm{C}_{1}-\mathrm{C}_{3}\right)$ versus inactive $\left(\mathrm{C}_{0}\right)$ ulcerative colitis on different doses of olsalazine

\begin{tabular}{|c|c|c|c|c|c|c|}
\hline & & \multirow{2}{*}{$\begin{array}{l}\text { Disease } \\
\text { activity }\end{array}$} & \multicolumn{4}{|c|}{ Olsalazine dose/day } \\
\hline & & & $\lg$ & $2 g$ & $3 g$ & $4 g$ \\
\hline $\begin{array}{l}\text { Serum: } \\
\text { Olsalazine }\end{array}$ & $\mathrm{mmol} / \mathrm{l}$ & $\begin{array}{l}\mathrm{C}_{1}-\mathrm{C}_{3} \\
\mathrm{C}_{1}\end{array}$ & $\begin{array}{l}0 \cdot 010(n=5) \\
0 \cdot 009(n=7)\end{array}$ & $\begin{array}{l}0 \cdot 016(n=22) \\
0 \cdot 017(n=6)\end{array}$ & $\begin{array}{l}0 \cdot 021(n=16) \\
0 \cdot 022(n=8)\end{array}$ & $\begin{array}{l}0 \cdot 026(n=16) \\
0 \cdot 024(n=10)\end{array}$ \\
\hline Faecal dialysate: & & & & & & \\
\hline 5-ASA & $\mathrm{mmol} / \mathrm{l}$ & $\begin{array}{l}\mathrm{C}_{1}-\mathrm{C}_{3} \\
\mathrm{C}_{0}\end{array}$ & $\begin{array}{l}6 \cdot 0(n=4) \\
4 \cdot 3(n=5)\end{array}$ & $\begin{array}{l}7 \cdot 8(n=18) \\
9 \cdot 5(n=5)\end{array}$ & $\begin{array}{l}12(n=12) \\
17(n=3)\end{array}$ & $\begin{array}{l}22(n=12) \\
25(n=9)\end{array}$ \\
\hline Ac-5-ASA & $\mathrm{mmol} / \mathrm{l}$ & $\begin{array}{l}\mathrm{C}_{1}-\mathrm{C}_{3} \\
\mathrm{C}_{0}\end{array}$ & $\begin{array}{l}6 \cdot 9(n=4) \\
12(n=5)\end{array}$ & $\begin{array}{l}8 \cdot 1(n=18) \\
16(n=5)\end{array}$ & $\begin{array}{l}7 \cdot 2(n=12) \\
11(n=3)\end{array}$ & $\begin{array}{c}9 \cdot 7(n=12) \\
12(n=9)\end{array}$ \\
\hline
\end{tabular}

5-ASA = 5-aminosalicylic acid; Ac-5-ASA = acetyl-5-aminosalicylic acid

treated with equal dosages of olsalazine, but the number of observations in the $\mathrm{CC}$ group precluded statistical comparison with the UC group. Concentrations of Ac-5-ASA in faecal dialysates were rather constant within the applied olsalazine dose range (from $1 \mathrm{~g} /$ day to $4 \mathrm{~g} /$ day), but concentrations of free 5-ASA, and thus also concentrations of total 5-ASA increased dose dependently (Table 3). Olsalazine concentrations in faecal dialysates were low (Table 3 ) compared with those of the split product (5-ASA) and its metabolite (Ac-5-ASA). The efficacy of azoreduction was estimated by calculation of the 'split ratio' - that is, the ratio between molar concentrations in faecal dialysates of total 5-ASA and total 5-ASA +5-ASA contents in unsplit olsalazine, respectively. The median split ratio was $99.4 \%$ $\left(\mathrm{Q}_{50}\right.$ interquartile range $93.8-100 \%$, range $40 \cdot 1$ $100 \%$ ) in all dialysates obtained from patients with UC. In $28 \%$ of all patients the split ratio was below $90 \%$, at least on one occasion, and more than half (six of 11) of these cases reported transient intolerance to the prescribed olsalazine dose. In eight of 11 patients experiencing tolerance problems the visit of reporting this event was at the scheduled time for collection of faecal dialysates (Table 2). In these cases the median split ratio was $49 \%$ (range $40-99 \%$ ) to be compared with a median of $95 \%$ (range $56-100 \%$ ) calculated from the lowest split ratios obtained at any time in the 29 patients not experiencing such a drug intolerance $(p<0 \cdot 05)$. Resolution of drug intolerance was associated with an increased split ratio $(p<0 \cdot 05)$.

During active disease the mean concentrations of 5-ASA and Ac-5-ASA in faecal dialysates tended to be lower than in dialysates from patients in remission (Table 4), but the number of observations on each dose of olsalazine was too small to permit statistical analysis. No differences between 5-ASA levels in patients with extensively located colitis and patients with 'left-sided' disease were found.

CONCENTRATIONS OF OLSALAZINE,

5-AMINOSALICYLIC ACID, AND ACETYL-5-

AMINOSALICYLIC ACID IN SERUM

The average serum concentrations of olsalazine, 5-ASA, and Ac-5-ASA in each patient were calculated for each dosage of olsalazine. The results are given in Table 5 for patients with UC. Dose dependent increases in the levels of olsalazine and 5-ASA were observed within the whole dose range, but no further increase in serum concentrations of Ac-5-ASA occurred beyond a dose of olsalazine equal to $3 \mathrm{~g} /$ day (Table 5). No statistically significant differences $(p>0.05)$ were found between serum concentrations of olsalazine, 5-ASA, and Ac-5-ASA in patients with UC and CC, respectively, when treated with an equal dosage of olsalazine. Similarly,

Table 5 Concentrations of olsalazine, 5-ASA, and Ac-5-ASA in serum of patients with ulcerative colitis: average in each patient for each dosage of olsalazine

\begin{tabular}{|c|c|c|c|c|c|}
\hline & & \multicolumn{4}{|l|}{ Olsalazine dose/day } \\
\hline & & $\lg (n=9)$ & $2 g(n=14)$ & $3 g(n=20)$ & $4 g(n=20)$ \\
\hline Olsalazine & $\mu \mathrm{mol} / \mathrm{l}$ & $9 \cdot 2(3 \cdot 4)[5 \cdot 4-15]$ & $16(6 \cdot 8)[3 \cdot 8-32]$ & $22(8 \cdot 1)[7 \cdot 9-39]$ & $25(11)[4 \cdot 5-48]$ \\
\hline 5-ASA & $\mu \mathrm{mol} / \mathrm{l}$ & $0.5(0.2)[<0.3-1 \cdot 0]$ & $1 \cdot 1(0.9)[<0 \cdot 3-3 \cdot 8]$ & $2 \cdot 4(1.6) \mid<0 \cdot 3-6 \cdot 8]$ & $3 \cdot 2(2 \cdot 4) \mid<0 \cdot 3-8 \cdot 8]$ \\
\hline Ac-5-ASA & $\mu \mathrm{mol} / \mathrm{l}$ & $2 \cdot 3(1 \cdot 3)[<0 \cdot 3-4 \cdot 0]$ & $3.9(2.4)[<0.3-9.6]$ & $5 \cdot 7(2.9)[1.8-14]$ & $5 \cdot 7(3 \cdot 2) \mid<0 \cdot 3-12]$ \\
\hline
\end{tabular}

5-ASA = 5-aminosalicylic acid; Ac-5-ASA = acetyl-5-aminosalicylic acid. Values represent means (SD) [range]. 
Table 6 Concentrations of $P G E_{2}$ in faecal dialysates and $P G E_{2}$ and $L T B_{4}$ in the rectal lumen

\begin{tabular}{|c|c|c|c|c|}
\hline Patients & Study day & $\begin{array}{l}\text { Faecal PGE } \\
\text { concentrations } \\
\text { (ng/ml) }\end{array}$ & $\begin{array}{l}\text { Rectal PGE } E_{2} \\
\text { concentrations }{ }^{\dagger} \\
(\text { ng/ml })\end{array}$ & $\begin{array}{l}\text { Rectal } L T B_{4} \\
\text { concentrations } \ddagger \\
\text { (ng/ml) }\end{array}$ \\
\hline \multicolumn{5}{|l|}{ Ulcerative colitis } \\
\hline \multirow[t]{3}{*}{ (SAZ refractory, $n=23$ ) } & Entry & $1.65(1.80)[0.07-4.48]$ & $16 \cdot 0(15 \cdot 3)[0 \cdot 29-58 \cdot 5]$ & $3.0(3.2)[<0.5-9.9]$ \\
\hline & Month 6 & $0.44(1.03)[0.05-4.72] \S$ & $8 \cdot 1(12 \cdot 3)[0 \cdot 05-42 \cdot 8] \S$ & $2 \cdot 7(4.7)[<0.5-20.4]$ \\
\hline & Month 12 & $0.77(1.09)[0.06-3.73] \S$ & $13.6(15 \cdot 4)[0 \cdot 12-49 \cdot 0]$ & $2.0(2.1) \mid<0.5-8.7]$ \\
\hline \multirow{3}{*}{ (SAZ intolerant, $n=8$ ) } & Entry & $1 \cdot 09(1 \cdot 18)[0 \cdot 10-3 \cdot 18]$ & $8 \cdot 5(15 \cdot 0)[0 \cdot 31-42 \cdot 0]$ & $1.6(2.6)[<0.5-7.0]$ \\
\hline & Month 6 & $0.48(0.85)[0.04-2.55]$ & $5 \cdot 7(11 \cdot 9)[0 \cdot 15-32 \cdot 6]$ & $0.9(1 \cdot 3)[<0 \cdot 5-3 \cdot 1]$ \\
\hline & Month 12 & $0.16(0.05)[0.08-0.22] \S$ & $1 \cdot 6(2 \cdot 0)[0 \cdot 32-5 \cdot 3]$ & $2.2(2.0)[<0.5-5.4]$ \\
\hline \multirow[t]{3}{*}{ Crohn's colitis $(n=9)$} & Entry & $1.76(1.94)[0.19-4.79]$ & $4 \cdot 0(5 \cdot 1)[0 \cdot 3-16 \cdot 3]$ & $0.5(0.4)[<0.5-1.5]$ \\
\hline & Month 6 & $0.70(0 \cdot 68)[0.08-1.81]$ & $5 \cdot 0(4 \cdot 8)[0 \cdot 4-13 \cdot 0]$ & $1 \cdot 4(1 \cdot 6) \mid<0 \cdot 5-4 \cdot 0]$ \\
\hline & Month 12 & $1.23(2.06)[0.04-5.39]$ & $3.0(5 \cdot 7)[0 \cdot 1-14 \cdot 6]$ & $0.7(0.6)<0.5-1.5]$ \\
\hline
\end{tabular}

Values represent mean (SD) [range]. ${ }^{*}$ Normal range: $<0 \cdot 5 \mathrm{ng} / \mathrm{ml} .{ }^{18}+$ Normal range: $<0 \cdot 6 \mathrm{ng} / \mathrm{ml} .{ }^{17} \ddagger$ Normal range: $<0 \cdot 5 \mathrm{ng} / \mathrm{ml} .{ }^{17} \S \mathrm{Statistically}$ significant $(\mathrm{p}<0.05$; paired $t$ test $) . \mathrm{SAZ}=$ sulphasalazine.

no statistically significant differences $(\mathrm{p}>0 \cdot 05)$ were found between levels of olsalazine in patients with active disease and patients in remission (Table 4), in patients with pancolitis and patients with 'left-sided' disease, in patients refractory to sulphasalazine and patients intolerant of sulphasalazine, or in patients having had continuously active disease during the previous year and those having had intermittently active disease. In individual patients on a stable dose of olsalazine no increase in serum concentrations of the unsplit drug or its metabolites were observed in the long term. Thus for each dose level of olsalazine (kept constant for at least three weeks) the initial serum concentrations measured in individual patients were taken as baseline values and compared with those obtained at subsequent visits unless the dosage had been changed. No differences from baseline values were observed $(p>0.05)$.

EFFECTS ON PROSTAGLANDIN E 2 AND

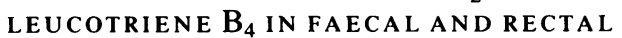

DIALYSATES

The trend in levels of $\mathrm{PGE}_{2}$ in faecal and rectal dialysates was a significant decrease with time in patients with UC, whether they were refractory to or intolerant of sulphasalazine (Table 6), whereas no decrease was disclosed in the levels of rectal $\mathrm{LTB}_{4}$. Concentrations of $\mathrm{PGE}_{2}$ and $\mathrm{LTB}_{4}$ were significantly raised in patients with active UC $\left(\mathrm{C}_{1}-\mathrm{C}_{3}\right)$ compared to those obtained in patients in remission $\left(\mathrm{C}_{0}\right)$. In 13 UC patients, in whom remission never occurred (treatment failures), pretrial rectal $\mathrm{PGE}_{2}$ concentrations were significantly raised $(p<0.05)$ compared with those observed in patients not classified as treatment failures. The rectal $\mathrm{PGE}_{2}$ concentrations in treatment failures persisted markedly increased during the medication period, whereas those observed in the remaining cases decreased toward the normal range. Thus also post-trial rectal $\mathrm{PGE}_{2}$ concentrations were increased in treatment failures $(p<0.05)$. All but one of seven patients with pretreatment rectal $\mathrm{PGE}_{2}$ concentrations $>30 \mathrm{ng} / \mathrm{ml}$ were classified as treatment failures.

By contrast, no statistically significant trends were observed in $\mathrm{PGE}_{2}$ or $\mathrm{LTB}_{4}$ concentrations in patients with CC (Table 6).

\section{ESTIMATES ON EFFICACY}

Thirteen patients with UC were regarded as treatment failures - that is, clinical and sigmoidoscopic remission was never obtained. This outcome was observed in one of eight patients intolerant of sulphasalazine and in 12 of 23 patients refractory to sulphasalazine $(p=0 \cdot 12$, Fisher's exact test). In six cases the disease was 'left-sided', whereas seven cases had a pancolitis. In the remaining patients a relapse occurred on at least one occasion: four experienced a relapse on $1 \mathrm{~g} /$ day, two on $2 \mathrm{~g} /$ day, eight on $3 \mathrm{~g} /$ day, and two on $4 \mathrm{~g} /$ day.

All patients classified as treatment failures had been given the maximum dose of olsalazine of $4 \mathrm{~g} /$ day, except in three cases (Table 2; patient no 15, $31,34)$, in whom drug intolerance occurred and all had been treated for the whole 12 months' period, except those who were withdrawn prematurely, as described above.

Five of the nine patients with $\mathrm{CC}$ were classified as treatment failures - that is, a CDAI $<150$, without sigmoidoscopic evidence of inflammation, was never obtained.

\section{Discussion}

Previous studies have shown that small intestinal absorption and metabolism of olsalazine is minimal and that a single oral dose is completely recovered 
from ileostomy fluid..$^{26}$ In patients with inactive UC complete azoreduction of olsalazine occurs on $1 \mathrm{~g}$ bid and concentrations of 5-ASA in faecal dialysates, in fact, double when sulphasalazine is replaced by the same dose of olsalazine. ${ }^{16}$ Oral olsalazine $0.5 \mathrm{~g}$ bid appears more effective than placebo in preventing relapse in sulphasalazine intolerant patients ${ }^{27}$ and $1 \mathrm{~g}$ bid orally for two weeks is more effective than placebo in the treatment of mildly active UC. ${ }^{2 x}$ The major adverse effect in these preliminary clinical trials was loose or watery stools, ${ }^{27}$ which were observed only in $10 \%$ of patients. This complaint usually occurred in patients with extensively located colitis $^{27}$ and might be explained by the action of the unsplit olsalazine molecule that, unlike sulphasalazine, markedly increases ileostomy output. ${ }^{29}$ The efficacy of azoreduction in active disease is unknown, but indirect evidence points to a reduced azoreduction of sulphasalazine. . $^{3011}$ Among all it might be speculated that the intestinal transit time as well as the character of intestinal microflora depend on the extension and the severity of the disease and thus the distribution of olsalazine and its metabolites. This concept is supported by the present results showing that intolerance is associated with insufficient azoreduction. The increased incidence of diarrhoea observed in the present series most likely reflects the use of a higher dose of olsalazine than in a previous study. ${ }^{27}$. Symptoms of this type of intolerance call, therefore, for a temporary reduction of the dose and the problem is more readily handled in clinical practice than in controlled trials with a fixed dose regimen. Also the occurrence of diarrhoea, which often subsided spontaneously with continued therapy, suggests that the therapeutic effect of 5-ASA may influence colonic function to permit a more effective azoreduction.

The present results also show that high doses of olsalazine can be administered safely in the long term and that azoreduction of olsalazine is almost complete in the major proportion of patients, even during administration of the highest dose $(4 \mathrm{~g} /$ day $)$. In this pharmaceutical respect, the olsalazine capsules fulfil the anticipation of providing a highly effective means of delivery of 5-ASA to the colonic mucosa, even in active disease. The results accord with our previous experience in patients with inactive UC and in healthy controls. ${ }^{16}$ No other "second generation" candidate reported on and developed to replace sulphasalazine - whether azobound or a pharmaceutically modified free 5-ASA preparation ${ }^{232}$ - has hitherto been shown to provide colonic concentrations of 5-ASA in the same order of magnitude as those shown in the present study.

The findings of rather constant concentrations of Ac-5-ASA in faecal dialysates and dose dependently increasing concentrations of 5-ASA, indicate that saturation of the intraluminal acetylation capacity occurs at a low dosage. This may be clinically important, because a therapeutic effect of Ac-5-ASA has not been unequivocally established. ${ }^{3.34}$

The serum concentrations observed on olsalazine $1 \mathrm{~g} /$ day and $2 \mathrm{~g} /$ day are comparable with those reported in healthy controls. ${ }^{163^{36}}$ The results (Table 5 ) indicate a dose related increase in absorption of olsalazine and its metabolites, but do not suggest that cumulation occurs in the long term.

The demonstration of extremely high intraluminal levels of $\mathrm{PGE}_{2}$ in treatment failures accords with our previous findings ${ }^{1718}$ and suggests that these quantifications of local disease activity are useful predictors of the outcome. We propose such determinations should be used prospectively in clinical trials on drug efficacy in UC.

The design of the present study did not permit any estimation of a dose response effect or a correlation between faecal 5-ASA levels and response to treatment. In planning the study we chose for safety reasons the pragmatic viewpoint to include only 'problematic' patients, who were not satisfactorily managed by conventional treatment - that is, sulphasalazine and a short course of glucocorticoid, although olsalazine may prove to be a sulphasalazine alternative. More treatment failures occurred among patients refractory to sulphasalazine than among patients intolerant of sulphasalazine. The complete splitting of olsalazine and the high concentrations of free 5-ASA in faecal dialysates from sulphasalazine refractory patients, who did not experience a remission, and from patients who relapsed, although maintained on a 4-g dose of olsalazine, indicate that sulphasalazine resistance is not merely a question of dosage, at least in a range up to $10 \mathrm{~g} /$ day - that is, equal to $4 \mathrm{~g}$ /day of olsalazine.

In conclusion, prolonged administration of high doses of olsalazine to patients with UC and CC appears acceptably well tolerated. The drug is a very effective means of delivery of 5-ASA to the colonic mucosa and, despite some cases of therapeutic resistance to even high intraluminal concentrations of 5-ASA, olsalazine seems to be a drug particularly appropriate for testing the efficacy of 5-ASA through controlled trials in patients with UC and CC in the long term.

This work was presented, in part, at the Nineteenth Scandinavian Conference on Gastroenterology in Torshavn, Faroe Islands on May 29-31, 1986 (Scand J Gastroenterol [Abstract] 1986; 21 (suppl 120): 12). Klaus Bukhave received a grant from Pharmacia AB, Uppsala, Sweden, who also kindly supplied the olsalazine and carried out the drug analyses. The 
authors thank Grete Eskesen, Anne Hallander, Dorit Ibsen, Inge-Lise Løffval, and Lene Persson for providing excellent technical assistance and Rigmor Petersen for skilful secretarial assistance.

\section{References}

1 Goldman P. Will there be a next generation of sulfasalazine? Gastroenterology 1982; 83: 1138-41.

2 Peppercorn MA. Sulfasalazine. Pharmacology, clinical use, toxicity, and related new drug development. Ann Intern Med 1984; 101: 377-86.

$3 \mathrm{Klotz}$ U. Clinical pharmacokinetics of sulphasalazine, its metabolites and other prodrugs of 5-aminosalicylic acid. Clin Pharmacokinet 1985; 10: 285-302.

4 Dissanayake AS, Truelove SC. A controlled therapeutic trial of long-term maintenance treatment of ulcerative colitis with sulphasalazine (Salazopyrin). Gut 1973; 14: 923-6.

5 Riis P. A critical survey of controlled studies in the treatment of ulcerative colitis and Crohn's disease. Clin Gastroenterol 1980; 9: 351-69.

6 Taffet SL, Das KM. Sulfasalazine. Adverse effects and desensitisation. Dig Dis Sci 1982; 28: 833-42.

7 Das KM, Eastwood MA, McManus JPA, Sircus W. Adverse reactions during salicylazosulfapyridine therapy and the relation with drug metabolism and acetylator phenotype. $N$ Engl J Med 1973; 289: 491-5.

8 Azad Khan AH, Piris J, Truelove SC. An experiment to determine the active therapeutic moiety of sulphasalazine. Lancet 1977; ii: 892-5.

9 vanHees PAM, Bakker JH, vanTongeren JHM. Effect of sulphapyridine, 5-aminosalicylic acid, and placebo in patients with idiopathic proctitis: a study to determine the active therapeutic moiety of sulphasalazine. Gut 1980; 21: 632-5.

10 Klotz U, Maier K, Fischer C, Heinkel K. Therapeutic efficacy of sulfasalazine and its metabolites in patients with ulcerative colitis and Crohn's disease. $N$ Engl J Med 1980; 303: 1499-502.

11 Azad Khan AK, Howes DT, Piris J, Truelove SC. Optimum dose of sulphasalazine for maintenance treatment in ulcerative colitis. Gut 1980; 21 : 232-40.

12 Summers RW, Switz DM, Sessions JT, et al. National Cooperative Crohn's Disease Study: results of drug treatment. Gastroenterology 1979; 77: 847-69.

13 Truelove SC, Watkinson G, Draper G. Comparison of corticosteroid and sulphasalazine therapy in ulcerative colitis. Br Med J 1962; ii: 1708-11.

14 Danish 5-ASA Group. Topical 5-aminosalicylic acid versus prednisolone in ulcerative proctosigmoiditis. A randomized, double-blind multicenter trial. Dig Dis Sci 1987; 32: 598-602.

15 Campieri M, Lanfranchi GA, Bazzocchi G, et al. Treatment of ulcerative colitis with high-dose 5aminosalicylic acid enemas. Lancet 1981; ii: 270-1.

16 Lauritsen K, Hansen J, Ryde M, Rask-Madsen J. Colonic azodisalicylate metabolism determined by in vivo dialysis in healthy volunteers and patients with ulcerative colitis. Gastroenterology 1984; 86: 1496-500.

17 Lauritsen K, Laursen LS, Bukhave K, Rask-Madsen J.
Effects of topical 5-aminosalicylic acid and prednisolone on prostaglandin $E_{2}$ and leukotriene $B_{4}$ levels determined by equilibrium in vivo dialysis of rectum in relapsing ulcerative colitis. Gastroenterology 1986; 91: 837-44.

18 Lauritsen K, Laursen LS, Bukhave K, Rask-Madsen J. Intraluminal colonic levels of arachidonic acid metabolites in ulcerative colitis. Adv Prostaglandin Thromboxane Leukotriene Res 1987; 17: 347-52.

19 Binder V, Both H, Hansen PK, Hendriksen C, Kreiner $\mathrm{S}$, Torp-Pedersen $\mathrm{K}$. Incidence and prevalence of ulcerative colitis and Crohn's disease in the county of Copenhagen, 1962 to 1978. Gastroenterology 1982; 83: 563-8.

20 Winship DH, Summers RW, Singleton JW, et al. National Cooperative Crohn's Disease Study: study design and conduct of the study. Gastroenterology 1979; 77: 829-42.

21 Binder V. A comparison between clinical state, macroscopic and microscopic appearances of rectal mucosa, and cytologic picture of mucosal exudate in ulcerative colitis. Scand J Gastroenterol 1970; 5: 627-32.

22 Baron JH, Connell AM, Lennard-Jones JE. Variation between observers in describing mucosal appearances in proctocolitis. Br J Med 1961; i: 89-93.

23 Best WR, Becktel JM, Singleton JW. Rederived values of the eight coefficients of the Crohn's Disease Activity Index (CDAI). Gastroenterology 1979; 77: 843-6.

24 Bukhave K, Rask-Madsen J. Prostaglandin $E_{2}$ in jejunal fluids and its potential diagnostic value for selecting patients with indomethacin-sensitive diarrhoea. Eur $J$ Clin Invest 1981; 11: 191-7.

25 Bukhave K, Gréen K, Rask-Madsen J. Comparison of radioimmunological determinations with gas chromatography mass spectrometry dosage. A study of $\mathrm{PGE}_{2}$ and $\mathrm{PGF}_{2 \alpha}$ in gastrointestinal fluids. Biomed Mass Spectrom 1983; 10: 265-8.

26 Sandberg-Gertzén H, Ryde M, Järnerot G. Absorption and excretion of a single $1-\mathrm{g}$ dose of Azodisal sodium in subjects with ileostomy. Scand J Gastroenterol 1983; 18: 107-11.

27 Sandberg-Gertzén H, Järnerot G, Kraaz W. Azodisal sodium in the treatment of ulcerative colitis. A study of tolerance and relapse-prevention properties. Gastroenterology 1986; 90: 1024-30.

28 Selby WS, Barr GD, Ireland A, Mason CH, Jewell DP. Olsalazine in active ulcerative colitis. Br Med J 1985; 291: 1373-5.

29 Sandberg-Gertzén H, Järnerot G, Bukhave K, Lauritsen K, Rask-Madsen J. Effect of azodisal sodium and sulphasalazine on ileostomy output of fluid, $\mathrm{PGE}_{2}$, and $\mathrm{PGF}_{2 \alpha}$ in subjects with a permanent ileostomy. Gut 1986; 27: 1306-11.

30 Peppercorn MA, Goldman P. Distribution studies of salicylazosulfapyridine and its metabolites. Gastroenterology 1973; 64: 240-5.

31 vanHees PAM. Tuinte JHM, vanRossum JM, vanTongeren JHM. Influence of intestinal transit time on azo-reduction of salicylazosulphapyridine (Salazopyrin). Gut 1979; 20: 300-4.

32 Bondesen S, Rasmussen SN, Rask-Madsen J, et al. 5Aminosalicylic acid in the treatment of inflammatory 
bowel disease. A review. Acta Med Scand 1987; 221: 227-42.

33 Willoughby CP, Piris J, Truelove SC. The effect of topical $\mathrm{N}$-acetyl-5-aminosalicylic acid in ulcerative colitis. Scand J Gastroenterol 1980; 15: 715-9.

34 Binder V, Halskov S, Hvidberg E, et al. A controlled study of 5-acet-aminosalicylic acid (5-Ac-ASA) as enema in ulcerative colitis [Abstract]. Scand J Gastroenterol 1981; 16: 1122.
35 Willoughby CP, Aronson JK, Agback H, Bodin NO, Truelove SC. Distribution and metabolism in healthy volunteers of disodium azodisalicylate, a potential therapeutic agent for ulcerative colitis. Gut 1982; 23: 1081-7.

36 vanHogezand RA, vanHess PAM, Zwanenburg B, vanRossum JM, vanTongeren JHM. Disposition of disodium azodisalicylate in healthy subjects. A possible new drug for inflammatory bowel disease. Gastroenterology 1985; 88: 717-22. 